\title{
A 15-Year Study on $\mathrm{Up}_{4} \mathrm{~A}$ in Cardiovascular Disease
}

\author{
Zhichao Zhou $^{1 *}$ and Takayuki Matsumoto ${ }^{2}$ \\ 1 Division of Cardiology, Department of Medicine, Karolinska University Hospital, Karolinska Institutet, Stockholm, Sweden, \\ 2 Department of Physiology and Morphology, Institute of Medicinal Chemistry, Hoshi University, Tokyo, Japan
}

Keywords: $\mathrm{Up}_{4} \mathrm{~A}$, cardiovascular, purinergic receptor, adenosine, ATP

\section{INTRODUCTION}

In 2005, a novel dinucleotide uridine adenosine tetraphosphate $\left(\mathrm{Up}_{4} \mathrm{~A}\right)$ was identified in the endothelium thereby being recognized as a novel endothelium-derived factor (Jankowski et al., 2005). $\mathrm{Up}_{4} \mathrm{~A}$ is the first dinucleotide found in living organisms containing both a purine and a pyrimidine moieties (Jankowski et al., 2005). $\mathrm{Up}_{4} \mathrm{~A}$ is biosynthesized through vascular endothelial growth factor receptor (VEGFR) 2 in response to pharmacological and mechanical stimuli (Jankowski et al., 2013). The plasma concentrations of $\mathrm{Up}_{4} \mathrm{~A}$ in healthy subjects are in the

OPEN ACCESS

Edited by:

Francisco Ciruela,

University of Barcelona, Spain

Reviewed by:

Carla Cicala,

University of Naples Federico II, Italy

*Correspondence:

Zhichao Zhou

zhichao.zhou@ki.se;

zhzhou2015@gmail.com orcid.org/0000-0002-5107-6529

Specialty section:

This article was submitted to Experimental Pharmacology and Drug Discovery,

a section of the journal

Frontiers in Pharmacology

Received: 17 June 2020

Accepted: 23 July 2020

Published: 04 August 2020

Citation:

Zhou Z and Matsumoto T (2020)

A 15-Year Study on Up 4 A in

Cardiovascular Disease.

Front. Pharmacol. 11:1200.

doi: 10.3389/fphar.2020.01200 vasoactive range suggesting that $\mathrm{Up}_{4} \mathrm{~A}$ may contribute to cardiovascular regulation (Jankowski et al., 2005). Of importance, several pieces of evidence have reported that the plasma level of $U_{4} A$ is elevated in patients with hypertension and with chronic kidney diseases, and that $\mathrm{Up}_{4} \mathrm{~A}$ (via intraaortic bolus injection) increases mean arterial pressure in rats in vivo (Jankowski et al., 2005; Jankowski et al., 2007; Schuchardt et al., 2012). These observations suggest a potential role for $\mathrm{Up}_{4} \mathrm{~A}$ in the pathogenesis of cardiovascular disease.

During the following years, the research was focused on the vascular effect of $\mathrm{Up}_{4} \mathrm{~A}$ in different vascular beds of various species. This mainly includes the acute effect of $\mathrm{Up}_{4} \mathrm{~A}$ on vascular function in both health and various cardiovascular diseases including hypertension, atherosclerosis, myocardial infarction, and diabetes, and the trophic effect of $\mathrm{Up}_{4} \mathrm{~A}$ on vascular proliferation, migration, angiogenesis, and calcification (Matsumoto et al., 2015; Zhou et al., 2019). Up 4 A exerts biological effects by activating purinergic receptors (PRs) to regulate cardiovascular (dys)function. PRs are divided into P1R and P2R categories. Four subtypes of P1Rs (adenosine receptors) have been identified, namely A1R, $A_{2 A} R, A_{2 B} R$, and A3R. At least seven P2XRs, and eight P2YRs have been identified to date (Burnstock, 2017). In the vasculature, activation of A1R and A3R can induce contraction, whereas activation of $\mathrm{A}_{2 \mathrm{~A}} \mathrm{R}$ and $\mathrm{A}_{2 \mathrm{~B}} \mathrm{R}$ typically produce vascular relaxation (Zhou et al., 2019). In contrast to P1Rs, the effects of the activation of P2R subtypes may be tissue- and cell-dependent. In general, activation of P2R subtypes in endothelial cells are thought to induce vasodilation, while activation of P2Rs in smooth muscle cells can induce vasoconstriction (Zhou et al., 2019). Of note, the pharmacological action of $\mathrm{Up}_{4} \mathrm{~A}$ on vascular function and the $\mathrm{Up}_{4} \mathrm{~A}$-mediated purinergic signaling have been shown to be altered in cardiovascular disease (Zhou et al., 2019). However, the endogenous role of $\mathrm{Up}_{4} \mathrm{~A}$ in the regulation of cardiovascular homeostasis and particularly the role of $\mathrm{Up}_{4} \mathrm{~A}$ in the development and progression of cardiovascular disease remain largely unclear. This study briefly summarizes the available information regarding the vascular action of $\mathrm{Up}_{4} \mathrm{~A}$ and its mediated purinergic signaling in various cardiovascular diseases during a 15-year research period and raises critical questions and perspectives for the future research direction in order to better understand the biological role of $\mathrm{Up}_{4} \mathrm{~A}$ in the development of cardiovascular disease. 


\section{UP 4 A BIOSYNTHESIS AND CATABOLISM}

$\mathrm{Up}_{4} \mathrm{~A}$ is biosynthesized by activation of VEGFR2 in the endothelium (Jankowski et al., 2013). After incubation of ADP and UDP with VEGFR2, human dermal endothelial cells generate increasing concentrations of $U_{4} \mathrm{~A}$, while there is no $\mathrm{Up}_{4} \mathrm{~A}$ formation when incubating ADP and UDP with VEGFR1 or VEGFR3 (Jankowski et al., 2013). The domain of Tyr-1175 of VEGFR2 is essential for the enzymatic activity for $\mathrm{Up}_{4} \mathrm{~A}$ synthesis (Jankowski et al., 2013). $\mathrm{Up}_{4} \mathrm{~A}$ could facilitate VEGFR2-mediated signaling pathways e.g. p42/44 mitogenactivated protein kinase phosphorylation (Jankowski et al., 2013). Given that VEGFR2 is abundantly expressed in endothelial cells, the $\mathrm{Up}_{4} \mathrm{~A}$ biosynthesis may play a significant role in cardiovascular homeostasis.

In addition to endothelial cells, $\mathrm{Up}_{4} \mathrm{~A}$ was found to be generated in renal tubular cells, human liver hepatocellular carcinoma cells, human acute monocytic leukemia cells, and murine macrophage cells (Zhou et al., 2019). As these cells express VEGFR2, $\mathrm{Up}_{4} \mathrm{~A}$ synthesis is likely also mediated by activation of VEGFR2. It is of interest to know whether VEGFR2-expressing cells are generally capable of synthesizing $\mathrm{Up}_{4} \mathrm{~A}$. Of further importance, several cardiovascular diseases including diabetes have demonstrated an altered VEGFR2 expression and function (Fountas et al., 2015). Whether such alteration may affect $\mathrm{Up}_{4} \mathrm{~A}$ generation and subsequent purinergic activation accounting for the development and progression of disease remains unknown and warrants further studies.

Catabolism of $\mathrm{Up}_{4} \mathrm{~A}$ is poorly understood. Dinucleotides can be degraded to mononucleotides by ecto-nucleotidases (including CD39 and CD37) (Burnstock, 2017). These ectonucleotidases are ubiquitously present in different cells, including vascular endothelial and smooth muscle cells (Burnstock, 2017). This implies that $\mathrm{Up}_{4} \mathrm{~A}$ may be also degraded through those ecto-nucleotidases, and that the $\mathrm{Up}_{4} \mathrm{~A}$ mediated vascular effects can be exerted by its degradation products. However, existing evidence suggest that $\mathrm{Up}_{4} \mathrm{~A}$ mediated vascular effects are direct, but not indirect through its degradation or inhibition of purinergic enzymes as mentioned above (Zhou et al., 2019). It is speculated that the catabolism of $\mathrm{Up}_{4} \mathrm{~A}$ may be through other types of ecto-nucleotidases e.g. nucleotide pyrophosphatase/phosphodiesterases. Further studies are needed to explore this mechanism. Of note, activity of these nucleotidases are altered in cardiovascular disease (Burnstock, 2017; Zhou et al., 2020). It is of importance to know in the future studies whether altered nucleotidase activity may influence the catabolism of $\mathrm{Up}_{4} \mathrm{~A}$ contributing to the initiation and/or development of cardiovascular disease.

\section{UP $_{4}$ A AND VASCULAR ACTIONS}

Using pharmacological approach, the 15-year research on $\mathrm{Up}_{4} \mathrm{~A}$ has unveiled vascular effects of $\mathrm{Up}_{4} \mathrm{~A}$ in various cardiovascular diseases. The $\mathrm{Up}_{4} \mathrm{~A}$-mediated $\mathrm{PR}$ activation and possible downstream pathways have been characterized in hypertension, diabetes, atherosclerosis, and myocardial infarction. In addition, $\mathrm{Up}_{4} \mathrm{~A}$ exerts various trophic effects through activation of $\mathrm{P} 2 \mathrm{YRs}$ inducing angiogenesis in endothelial cells, proliferation and migration in smooth muscle cells, and development of calcification (Zhou et al., 2019). These chronic effects may also play a role for vascular remodeling and atherogenesis.

\section{Hypertension}

Vascular reactivity to $\mathrm{Up}_{4} \mathrm{~A}$ is altered in hypertension. In deoxycorticosterone acetate-salt rats, $\mathrm{Up}_{4} \mathrm{~A}$-induced contraction is heterogeneously affected among various vessels. Thus, $\mathrm{Up}_{4} \mathrm{~A}$ induced vascular contraction was increased in basilar, renal, and femoral arteries, but was decreased in small mesenteric arteries, and unchanged in thoracic aortas and pulmonary arteries (Matsumoto et al., 2011; Matsumoto et al., 2012). Activation of P2YR contributed to the increased $\mathrm{Up}_{4} \mathrm{~A}$-induced contraction in basilar, femoral, and renal arteries (Matsumoto et al., 2011; Matsumoto et al., 2012). In angiotensin II-induced hypertensive mice, $\mathrm{Up}_{4} \mathrm{~A}-$ induced contraction in aortas was decreased likely due to $\mathrm{P} 2 \mathrm{X}_{1} \mathrm{R}$ desensitization (Zhou et al., 2017b). These observations may imply that vascular PR activity rather than circulating $\mathrm{Up}_{4} \mathrm{~A}$ may determine the role of $\mathrm{Up}_{4} \mathrm{~A}$ in setting of hypertension. However, further investigations regarding the relationship between altered circulating $\mathrm{Up}_{4} \mathrm{~A}$ and vascular $\mathrm{PR}$ activity in hypertension are needed. In contrast to vasoconstrictor effect, $\mathrm{Up}_{4} \mathrm{~A}$ produces potent relaxation in porcine coronary small arteries (Zhou et al., 2013b; Sun et al., 2019). In a swine model with pressure-overloadinduced hypertension, $\mathrm{Up}_{4} \mathrm{~A}$-induced relaxation was impaired in coronary small arteries isolated from hypertensive swine compared to control. ARs other than $\mathrm{A}_{2 \mathrm{~A}} \mathrm{R}$ and $\mathrm{P}_{2} \mathrm{Y}_{12} \mathrm{R}$ among P2Rs are proposed contributing to the reduced relaxation to $\mathrm{Up}_{4} \mathrm{~A}$ in hypertensive swine (Zhou et al., 2018a).

\section{Diabetes}

Diabetes is an important risk factor for the development of cardiovascular diseases including atherosclerosis and ischemic heart disease (Pereira et al., 2018; Zhou et al., 2018b). Diabetesassociated vascular complications are the leading causes of increased morbidity and mortality worldwide (Zhou et al., 2018b). Up ${ }_{4} \mathrm{~A}$-induced contraction in renal arteries of healthy rats, which was enhanced in vessels from Goto-Kakizaki (GK) rats likely due to activation of suramin-sensitive P2Rs (Matsumoto et al., 2014). Up $\mathrm{u}_{4} \mathrm{~A}$-induced contraction was decreased in aortas and renal arteries of the Otsuka LongEvans Tokushima Fatty (OLETF) diabetic rats as compared to control Long-Evans Tokushima Otsuka (LETO) rats at basal tone (Matsumoto et al., 2016; Matsumoto et al., 2017). Of note, the $\mathrm{Up}_{4} \mathrm{~A}$-induced renal contraction in OLETF rats was increased with age and duration of diabetes, whereas the $\mathrm{Up}_{4} \mathrm{~A}$-induced contraction in LETO rats was not associated with age (Matsumoto et al., 2016). With elevated tone by phenylephrine, $\mathrm{Up}_{4} \mathrm{~A}$ produced a mild relaxation in aortas isolated from OLETF rats as compared to the vasoconstrictor effect by $\mathrm{Up}_{4} \mathrm{~A}$ in LETO rats (Matsumoto et al., 2017). The involvements of PRs in different vascular responses to $\mathrm{Up}_{4} \mathrm{~A}$ in 
this model need further investigations. However, $\mathrm{Up}_{4} \mathrm{~A}$ can stimulate other endothelium-derived factors e.g. vasoconstrictor prostanoids $\mathrm{PGF}_{2 \alpha}, \mathrm{PGE}_{2}$, and thromboxane $\left(\mathrm{TxA}_{2}\right)$ are generated in response to $\mathrm{Up}_{4} \mathrm{~A}$ to promote its contraction and nitric oxide is released to suppress $\mathrm{Up}_{4} \mathrm{~A}$ effects in OLETF rats (Matsumoto et al., 2017). Interestingly, $\mathrm{Up}_{4} \mathrm{~A}$-induced relaxation in coronary small arteries was maintained in swine with diabetes and endothelial dysfunction compared to normal swine (Zhou et al., 2017a). This is due to a balanced purinergic activation (reduced vasodilator $\mathrm{A}_{2 \mathrm{~A}} \mathrm{R}$ and $\mathrm{P} 2 \mathrm{X}_{7} \mathrm{R}$ vs. increased vasodilator $\left.\mathrm{P} 2 \mathrm{Y}_{1} \mathrm{R}\right)$ and endothelium-derived factor-mediated effects (vasodilator CYP 2C9 vs. vasoconstrictor CYP $2 \mathrm{C} 9$ and $\mathrm{TxA} 2$ ) in response to $\mathrm{Up}_{4} \mathrm{~A}$ (Zhou et al., 2017a).

\section{Coronary Atherosclerosis and Myocardial Infarction}

Plaque formation due to atherosclerosis in coronary vasculature is a major cause of ischemic heart disease. When the plaque ruptures, the ensuing thromboembolism may lead to ischemia and myocardial infarction (Marzilli et al., 2012). Despite all four ARs and many P2Rs are involved in the development of atherosclerosis and targeting $\mathrm{P}_{2} \mathrm{Y}_{12} \mathrm{R}$ is an effective strategy commonly used in patients with acute coronary syndrome (Burnstock, 2017), the experimental evidence for the involvement of PRs in coronary atherosclerosis is lacking. In coronary arteries isolated from ApoE knockout mice treated with a high fat diet, in which lesions were observed, $\mathrm{P}_{2} \mathrm{X}_{1} \mathrm{R}$ expression was decreased in endothelial cells, while $\mathrm{P} 2 \mathrm{X}_{1} \mathrm{R}$ expression remained unaltered in smooth muscle cells. Hence, the smooth muscle to endothelial cell ratio of $\mathrm{P} 2 \mathrm{X}_{1} \mathrm{R}$ was increased, suggesting a net vasoconstrictor effect of $\mathrm{P} 2 \mathrm{X}_{1} \mathrm{R}$ in coronary atherosclerosis (Teng et al., 2017). Indeed, infusion of $\mathrm{Up}_{4} \mathrm{~A}$ into isolated hearts from $A p o E$ knockout mice with high fat diet decreased coronary flow more as compared to hearts from control mice through activation of vasoconstrictor $\mathrm{P} 2 \mathrm{X}_{1} \mathrm{R}$ (Teng et al., 2017). In contrast to ex vivo experiments, a bolus i.v. injection of $\mathrm{Up}_{4} \mathrm{~A}$ increased coronary blood flow to a similar extent between control and atherosclerotic mice (Teng et al., 2017). This vasodilator effect of $\mathrm{Up}_{4} \mathrm{~A}$ is not influenced by the hemodynamic changes by the drug infusion. However, the possibility of a $\mathrm{Up}_{4} \mathrm{~A}$ degradation to purine or adenosine to induce coronary vasodilation in vivo condition remain undetermined, which warrants further investigations. In swine after myocardial infarction, the sensitivity of the coronary small arteries to $\mathrm{Up}_{4} \mathrm{~A}$ was reduced (Zhou et al., 2013a). The reduced vasodilator response to $\mathrm{Up}_{4} \mathrm{~A}$ is due to a reduced contribution of P1R ( $A_{2 B} R$ was proposed to be involved) (Zhou et al., 2013a).

\section{CONCLUSIONS AND PERSPECTIVE}

The 15-year research on $\mathrm{Up}_{4} \mathrm{~A}$ in cardiovascular system has yielded fruitful outcomes. $\mathrm{Up}_{4} \mathrm{~A}$ produces both short-term and long-term vascular effects through both P1R and P2R. The $\mathrm{Up}_{4} \mathrm{~A}$-induced effects not only depend on various vascular beds but also different species. The involvement of PRs in response to $\mathrm{Up}_{4} \mathrm{~A}$ is altered in various cardiovascular diseases. However, endogenous role of $\mathrm{Up}_{4} \mathrm{~A}$ in the regulation of vascular function remains unclear. Although the vasoactive effect of $\mathrm{Up}_{4} \mathrm{~A}$ may depend on receptor activity, the contribution of the $\mathrm{Up}_{4} \mathrm{~A}$ plasma levels to vascular (dys)function in cardiovascular disease warrants further investigations. Future research directions need to focus on the following aspects to better understand the role of $\mathrm{Up}_{4} \mathrm{~A}$ in the development and progression of cardiovascular disease: 1) Does the altered plasma levels of $\mathrm{Up}_{4} \mathrm{~A}$ in cardiovascular disease merely serve as a diagnostic biomarker, and/or can endogenous $\mathrm{Up}_{4} \mathrm{~A}$ (including local concentration of $\mathrm{Up}_{4} \mathrm{~A}$ e.g. in coronary microcirculation) activate corresponding PRs serving as a causative factor? What are causal factors and mechanisms underlying regulation of local/circulating $\mathrm{Up}_{4} \mathrm{~A}$ levels? 2) Given that $\mathrm{Up}_{4} \mathrm{~A}$ can activate both P1Rs and P2Rs expressed in different cells of the cardiovascular system, it remains to be investigated which receptors play an essential role. 3) Can $\mathrm{Up}_{4} \mathrm{~A}$ biosynthesis and its mediated main purinergic signaling be targeted for the treatment of cardiovascular disease? Whether targeting a single receptor or multiple receptors at the same time yields in the most effective therapeutic effects. 4) What are the mechanisms underlying the $\mathrm{Up}_{4} \mathrm{~A}$-mediated effect in vivo condition? 5) Can $\mathrm{Up}_{4} \mathrm{~A}$ mediated vascular effect be eventually translated into human situation? It may take many other 15 years to address all these important questions and concerns. However, the successful characterization of vascular effect of $\mathrm{Up}_{4} \mathrm{~A}$ and $\mathrm{PRs}$ involved in cardiovascular disease mentioned in the present study have paved the way for the next research step.

\section{DEDICATION}

This study is dedicated to the memory of Geoffrey Burnstock from Royal Free and University College Medical School, London, United Kingdom, who peacefully passed away on June $3^{\text {rd }} 2020$.

\section{AUTHOR CONTRIBUTIONS}

$\mathrm{ZZ}$ conceived the study. ZZ and TM wrote and edited the manuscript. All authors contributed to the article and approved the submitted version.

\section{FUNDING}

This work was supported by the Swedish Heart and Lung Foundation (20190341 to ZZ), the Loo and Hans Ostermans Foundation (2018-01213 and 2020-01209 to ZZ), and the Lars Hiertas Minne Foundation (FO2018-0156 to ZZ). 


\section{REFERENCES}

Burnstock, G. (2017). Purinergic Signaling in the Cardiovascular System. Circ. Res. 120 (1), 207-228. doi: 10.1161/CIRCRESAHA.116.309726

Fountas, A., Diamantopoulos, L. N., and Tsatsoulis, A. (2015). Tyrosine Kinase Inhibitors and Diabetes: A Novel Treatment Paradigm? Trends Endocrinol. Metab. 26 (11), 643-656. doi: 10.1016/j.tem.2015.09.003

Jankowski, V., Tolle, M., Vanholder, R., Schonfelder, G., van der Giet, M., Henning, L., et al. (2005). Uridine adenosine tetraphosphate: a novel endothelium- derived vasoconstrictive factor. Nat. Med. 11 (2), 223-227. doi: $10.1038 / \mathrm{nm} 1188$

Jankowski, V., Meyer, A. A., Schlattmann, P., Gui, Y., Zheng, X. L., Stamcou, I., et al. (2007). Increased uridine adenosine tetraphosphate concentrations in plasma of juvenile hypertensives. Arterioscler. Thromb. Vasc. Biol. 27 (8), 1776-1781. doi: 10.1161/ATVBAHA.107.143958

Jankowski, V., Schulz, A., Kretschmer, A., Mischak, H., Boehringer, F., van der Giet, M., et al. (2013). The enzymatic activity of the VEGFR2 receptor for the biosynthesis of dinucleoside polyphosphates. J. Mol. Med. (Berl) 91 (9), 10951107. doi: 10.1007/s00109-013-1036-y

Marzilli, M., Merz, C. N., Boden, W. E., Bonow, R. O., Capozza, P. G., Chilian, W. M., et al. (2012). Obstructive coronary atherosclerosis and ischemic heart disease: an elusive link! J. Am. Coll. Cardiol. 60 (11), 951-956. doi: 10.1016/j.jacc.2012.02.082

Matsumoto, T., Tostes, R. C., and Webb, R. C. (2011). Uridine adenosine tetraphosphate-induced contraction is increased in renal but not pulmonary arteries from DOCA-salt hypertensive rats. Am. J. Physiol. Heart Circ. Physiol. 301 (2), H409-H417. doi: 10.1152/ajpheart.00084.2011

Matsumoto, T., Tostes, R. C., and Webb, R. C. (2012). Alterations in vasoconstrictor responses to the endothelium-derived contracting factor uridine adenosine tetraphosphate are region specific in DOCA-salt hypertensive rats. Pharmacol. Res. 65 (1), 81-90. doi: 10.1016/j.phrs.2011.09.005

Matsumoto, T., Watanabe, S., Kawamura, R., Taguchi, K., and Kobayashi, T. (2014). Enhanced uridine adenosine tetraphosphate-induced contraction in renal artery from type 2 diabetic Goto-Kakizaki rats due to activated cyclooxygenase/thromboxane receptor axis. Pflugers Arch. 466 (2), 331-342. doi: 10.1007/s00424-013-1330-0

Matsumoto, T., Goulopoulou, S., Taguchi, K., Tostes, R. C., and Kobayashi, T. (2015). Constrictor prostanoids and uridine adenosine tetraphosphate: vascular mediators and therapeutic targets in hypertension and diabetes. $\mathrm{Br}$. J. Pharmacol. 172 (16), 3980-4001. doi: 10.1111/bph.13205

Matsumoto, T., Watanabe, S., Ando, M., Yamada, K., Iguchi, M., Taguchi, K., et al. (2016). Diabetes and Age-Related Differences in Vascular Function of Renal Artery: Possible Involvement of Endoplasmic Reticulum Stress. Rejuvenation Res. 19 (1), 41-52. doi: 10.1089/rej.2015.1662

Matsumoto, T., Kobayashi, S., Ando, M., Iguchi, M., Takayanagi, K., Kojima, M., et al. (2017). Alteration of Vascular Responsiveness to Uridine Adenosine Tetraphosphate in Aortas Isolated from Male Diabetic Otsuka Long-Evans Tokushima Fatty Rats: The Involvement of Prostanoids. Int. J. Mol. Sci. 18 (11), 2378. doi: 10.3390/ijms18112378

Pereira, C. A., Carneiro, F. S., Matsumoto, T., and Tostes, R. C. (2018). Bonus Effects of Antidiabetic Drugs: Possible Beneficial Effects on Endothelial Dysfunction, Vascular Inflammation and Atherosclerosis. Basic Clin. Pharmacol. Toxicol. 123 (5), 523-538. doi: 10.1111/bcpt.13054

Schuchardt, M., Tolle, M., Prufer, J., Prufer, N., Huang, T., Jankowski, V., et al. (2012). Uridine adenosine tetraphosphate activation of the purinergic receptor
P2Y enhances in vitro vascular calcification. Kidney Int. 81 (3), 256-265. doi: $10.1038 / \mathrm{ki} .2011 .326$

Sun, C., Jiao, T., Merkus, D., Duncker, D. J., Mustafa, S. J., and Zhou, Z. (2019). Activation of adenosine $\mathrm{A} 2 \mathrm{~A}$ but not $\mathrm{A} 2 \mathrm{~B}$ receptors is involved in uridine adenosine tetraphosphate-induced porcine coronary smooth muscle relaxation. J. Pharmacol. Sci. 141 (1), 64-69. doi: 10.1016/j.jphs.2019.09.006

Teng, B., Labazi, H., Sun, C., Yang, Y., Zeng, X., Mustafa, S. J., et al. (2017). Divergent coronary flow responses to uridine adenosine tetraphosphate in atherosclerotic ApoE knockout mice. Purinergic Signal 13 (4), 591-600. doi: 10.1007/s11302-017-9586-Z

Zhou, Z., de Wijs-Meijler, D., Lankhuizen, I., Jankowski, J., Jankowski, V., Jan Danser, A. H., et al. (2013a). Blunted coronary vasodilator response to uridine adenosine tetraphosphate in post-infarct remodeled myocardium is due to reduced P1 receptor activation. Pharmacol. Res. 77, 22-29. doi: 10.1016/ j.phrs.2013.08.007

Zhou, Z., Merkus, D., Cheng, C., Duckers, H. J., Jan Danser, A. H., and Duncker, D. J. (2013b). Uridine adenosine tetraphosphate is a novel vasodilator in the coronary microcirculation which acts through purinergic P1 but not P2 receptors. Pharmacol. Res. 67 (1), 10-17. doi: 10.1016/j.phrs.2012.09.011

Zhou, Z., Sorop, O., de Beer, V. J., Heinonen, I., Cheng, C., Jan Danser, A. H., et al. (2017a). Altered purinergic signaling in uridine adenosine tetraphosphateinduced coronary relaxation in swine with metabolic derangement. Purinergic Signal 13 (3), 319-329. doi: 10.1007/s11302-017-9563-6

Zhou, Z., Yadav, V. R., Sun, C., Teng, B., and Mustafa, J. S. (2017b). Impaired Aortic Contractility to Uridine Adenosine Tetraphosphate in Angiotensin IIInduced Hypertensive Mice: Receptor Desensitization? Am. J. Hypertens. 30 (3), 304-312. doi: 10.1093/ajh/hpw163

Zhou, Z., Lankhuizen, I. M., van Beusekom, H. M., Cheng, C., Duncker, D. J., and Merkus, D. (2018a). Uridine Adenosine Tetraphosphate-Induced Coronary Relaxation Is Blunted in Swine With Pressure Overload: A Role for Vasoconstrictor Prostanoids. Front. Pharmacol. 9, 255. doi: 10.3389/ fphar.2018.00255

Zhou, Z., Mahdi, A., Tratsiakovich, Y., Zahoran, S., Kovamees, O., Nordin, F., et al. (2018b). Erythrocytes From Patients With Type 2 Diabetes Induce Endothelial Dysfunction Via Arginase I. J. Am. Coll. Cardiol. 72 (7), 769-780. doi: 10.1016/ j.jacc.2018.05.052

Zhou, Z., Matsumoto, T., Jankowski, V., Pernow, J., Mustafa, S. J., Duncker, D. J., et al. (2019). Uridine adenosine tetraphosphate and purinergic signaling in cardiovascular system: An update. Pharmacol. Res. 141, 32-45. doi: 10.1016/ j.phrs.2018.12.009

Zhou, R., Dang, X., Sprague, R. S., Mustafa, S. J., and Zhou, Z. (2020). Alteration of purinergic signaling in diabetes: Focus on vascular function. J. Mol. Cell Cardiol. 140, 1-9. doi: 10.1016/j.yjmcc.2020.02.004

Conflict of Interest: The authors declare that the research was conducted in the absence of any commercial or financial relationships that could be construed as a potential conflict of interest.

Copyright (c) 2020 Zhou and Matsumoto. This is an open-access article distributed under the terms of the Creative Commons Attribution License (CC BY). The use, distribution or reproduction in other forums is permitted, provided the original author(s) and the copyright owner(s) are credited and that the original publication in this journal is cited, in accordance with accepted academic practice. No use, distribution or reproduction is permitted which does not comply with these terms. 